\title{
O CURRÍCULO GEOGRÁFICO DOS ANOS INICIAIS: DA SUA HISTÓRIA ÀS SUAS DIRETRIZES
}

\author{
The geographic curriculum of the Early Years: from its history to its guidelines \\ Henrique Silva Gorziza* \\ * Doutorando no Programa de Pós-graduação em Geografia - \\ Universidade Federal do Rio Grande do Sul \\ henriquegorziza@gmail.com
}

Recebido em 15/08/2018. Aceito para publicação em 25/08/2018.

Versão online publicada em 20/11/2018 (http://seer.ufrgs.br/paraonde)

\begin{abstract}
Resumo: 0 trabalho introduz e caracteriza o ensino dos conteúdos geográficos nos Anos Iniciais do Ensino Fundamental. Apresenta um breve histórico da Geografia trabalhada nos currículos de acordo com a Lei de Diretrizes e Bases que instituiu os documentos oficiais do país. Objetiva desconstruir algumas particularidades existentes nesses documentos, visando também entender o currículo através de uma análise teórica sobre o seu papel desempenhado no ensino da geografia escolar. Por meio da análise realizada, foi possível compreender lacunas que caracterizam um desencontro nos apontamentos presentes nas suas diretrizes e orientações, as quais nos levam a refletir sobre o currículo existente nas rotinas escolares. Foi possível evidenciar a importância do poder do currículo escolar na construção de saberes e valores.
\end{abstract}

Palavras-chave: Conteúdos geográficos; documentos curriculares; Anos Iniciais.

\begin{abstract}
The paper introduces and characterizes the teaching of geographic contents in the Early Years of Elementary School. It presents a brief history of Geography taught in the curricula according to the Law of Guidelines and Bases that instituted the official documents of the country. It aims to deconstruct some particularities in these documents and understand the curriculum through a theoretical analysis about its role played in the teaching of school geography. Through the analysis, it was possible to verify the existence of gaps that characterize a mismatch in the notes presented in its guidelines, which lead us to reflect on the current curriculum of school routines. It was possible to highlight the importance of the power of the school curriculum in the construction of knowledge and values.
\end{abstract}

Key-words: Geographic contents; Early Years; Curricular documents.

\section{Introdução}

O presente trabalho compreende discussões teóricas que introduzem e caracterizam o contexto relativo ao currículo geográfico dos Anos Iniciais, desde sua história às suas diretrizes, que tende à valorização dos conteúdos geográficos nos currículos que abrangem esta disciplina nos anos iniciais do Ensino Fundamental.

Assim, das fundamentações teóricas evidenciadas no interior do trabalho foram organizadas de forma engendrada, assuntos que dizem respeito ao tema abordando e trazendo, inicialmente, um breve histórico da Geografia nos Anos Iniciais no Brasil, em seguida do que ampara essa disciplina conforme a Lei de Diretrizes e Bases (LDB) que instituiu as Diretrizes Curriculares Nacionais Gerais para a Educação Básica (DCNGEB), as Diretrizes Curriculares Nacionais do Ensino Fundamental (DCNEF), e os Parâmetros Curriculares Nacionais(PCN"s).

Desconstruir as particularidades existentes no currículo da geografia escolar dos anos iniciais centra o objetivo desse trabalho que, para tanto, faz-se necessário, entender o currículo por meio de uma análise teórica, seu papel e o que influencia nas suas alterações. Pois, problematizar a geografia no cenário curricular dos anos iniciais desponta o interesse de delimitar, a partir desses documentos, a intenção dos seus discursos que, por sua vez, consistem numa produção de sentidos que, geralmente, servem como suporte norteador aos professores responsáveis de ministrar o conteúdo dos 
componentes curriculares no referido nível de escolaridade.

Salienta-se para o presente trabalho, a delimitação até o período aludido considerando, através da LDB de 1996, suas orientações curriculares existentes nas DCNGEB, DCNEF e PCN's, como documentos oficiais. Posto que, suas orientações validam o aporte necessário a todos os sujeitos envolvidos nas estruturas organizacionais concernentes aos anos iniciais do ensino básico, apesar de já constar, no presente momento, como documento oficial preliminar, a Base Nacional Comum Curricular - BNCC, em sua segunda versão, publicada em abril de 2016.

\section{Desenvolvimento}

Refletirmos sobre a geografia escolar dos Anos Iniciais demanda repensarmos seu trajeto histórico até os dias atuais. Embora muitos estudos sobre os anos iniciais vem sendo levantados, o assunto antepara um olhar cauteloso com relação as dificuldades que os professores defrontam-se na rotina escolar no referido nível de ensino em todo país, por exemplo. Desta forma, o estudo a respeito da identificação da ciência geográfica existente nessas estruturas curriculares pode ser melhor compreendido a partir da perspectiva histórica sobre o percurso da disciplina de geografia nos anos iniciais que herda uma gama complexa de obstáculos quanto a sua inserção na educação básica.

Esta teve seu marco inicial, em 1934, quando foi criada na Universidade de São Paulo a Faculdade de Filosofia, Letras e Ciências Humanas e promulgada sob a Lei Orgânica do Ensino Primário e da Lei Orgânica do Ensino Normal, pelo Decreto-Lei n. o 8.529. Em 1946, sendo incluída de acordo com a Escola Nova, que tinha o intuito de contribuir para um crescimento pleno do aluno, além da função de escrita e leitura. Em 1961, foi promulgada a Lei de Diretrizes e Bases - LDB, n. o 4.024, que ofereceu orientações curriculares mais flexíveis. Entretanto, em 1971 é promulgada a Lei de Diretrizes e Bases - LBD, n. o 5.692, que alinhou o sistema educacional às intenções do governo condizentes aos princípios vividos na época da Ditadura Militar. Neste momento, a Geografia era substituída pela disciplina de Educação Moral e Cívica - EMC, que atendia com maior eficácia, os objetivos políticos e ideológicos do governo.

Após, com a LDB de 1971, a disciplina de Geografia junto com a disciplina de História, foram substituídas pela disciplina de Estudos Sociais imposta pelo regime autoritário que ocasionava um desinteresse cultural e, por consequência, foram reduzidos seus conteúdos. Nas décadas de 1980 e 1990, movimentos passaram a protestar pelo fim da disciplina de Estudos Sociais e reaver as disciplinas de Geografia e História no currículo. Portanto, em 1993, a disciplina de Estudos Sociais é extinta e, são retomadas as disciplinas de Geografia e História, conforme reporta (CAMPOS, 2011).

Todavia, foi com a LDB de 1996, n. o 9394, que foi reestruturado o ensino do país em moldes estipulados ao modelo de produção vigente, o capitalista, carecido de políticas públicas educacionais mais eficazes competentes a um ensino mais qualificado, no ano próximo, em 1997, os Parâmetros Curriculares Nacionais - PCN"s foram enunciados na premissa de orientar discussões nas escolas da Educação Básica, trazendo objetivos e proposições didáticas a todos os níveis da escolarização. Neste momento, também, é mister salientar a conquista da Geografia como espaço legal no currículo dos Anos Iniciais do Ensino Fundamental. Embora os PCN"s terem assegurado um espaço mais dedicado à Geografia mediante ao que se previa até a década de 1990, ainda se prenunciava junto da História quando organizadas no documento em apreço. Foi então que, através de reivindicações das Associações de Geografia e de História, a AGB e a ANPUH, em 1997, que a disciplina de Geografia, por vez, dissociou-se disciplina de História.

Obtendo essa noção histórica sobre a disciplina de geografia, considerar políticas públicas enquanto orientações a respeito do currículo do E.F, neste momento que se pensa a importância da Geografia, é extremante salutar. Valendo-nos da publicação efetiva dos PCN"s em 1997 quando, a Geografia recebeu um espaço como disciplina no currículo escolar, é que podemos debater acerca de uma Geografia, enquanto seu espaço legalmente amparado. Porém, cabe salientar que, apesar dos PCN"s para os anos iniciais serem consolidados como documentos norteadores, entende-se que a elaboração dos mesmos deu-se de forma precoce com relação à LDB de 1996, que estabelecia as estruturas e funcionamentos da educação tornando obrigatória a determinação de diretrizes para a educação básica do país e, consequentemente, delineando o currículo no país.

ParaOnde!?, Porto Alegre, v.10, n.2, p.142-148, 2018. Edição Especial com artigos publicados originalmente na XII ENANPEGE http://seer.ufrgs.br/paraonde 
Com propósito de atenuar tal atropelo, a Resolução CEB n 2 de 1998 foi aprovada e passa a instituir as Diretrizes Curriculares Nacionais para o Ensino Fundamental e o Parecer CNE/CEB n ${ }^{\circ} 11$ de 2010 que dispõe sobre as Diretrizes Curriculares Nacionais para o Ensino Fundamental de nove (9) anos. Diretrizes estas se tratam do conjunto de doutrinas que estabelecem princípios, fundamentos e procedimentos para a Educação Básica, servindo de suporte às escolas do país para o desenvolvimento e a organização de suas propostas pedagógicas e é mais específico quanto a organização do Ensino fundamental, pois formula uma significativa modificação relacionada às áreas de conhecimento para os módulos, isto é, a partir da modificação em 2006, a estrutura desta etapa da Educação Básica que era de oito (8) anos passou a ser de nove (9) anos de duração e a entrada que era de sete (7) anos passou para seis (6) anos. Decorrente desta organização houve, por parte das escolas, a necessidade de um novo currículo e de novos projetos políticos pedagógicos indo ao encontro do que demandava os desafios propostos ao sistema de educação brasileiro.

Continuando os apontamentos dos pareceres, ainda sobre o Parecer CNE/CEB n¹1/2010, os componentes curriculares obrigatórios do Ensino Fundamental organizaram-se de forma diferente da resolução anterior em relação às áreas de conhecimento listadas no seguinte ordenamento:

"I - Linguagens:

a) Língua Portuguesa

b) Língua materna, para populações indígenas

c) Língua Estrangeira moderna

d) Arte

e) Educação Físi

II - Matemática

III - Ciências da Natureza

IV - Ciências Humanas:

a) História

b) Geografia

V - Ensino Religioso." (Parecer CNE/CEB nº 11/2010).

Imbricados na desconstrução das diretrizes curriculares, mediante o Artigo 15 afirmado pela base nacional comum das DCN, temos claro a partir do olhar de Straforini, "que a área Ciências Humanas será formada por Geografia e História" e, no Artigo 30, "que nos três anos iniciais do Ensino Fundamental deva-se assegurar o acesso à alfabetização e o letramento, às múltiplas linguagens, à Matemática, à Ciência, à História e à Geografia", (2016, p. 163).

Posto isto e, sobre as DCNGEB que presidem as DCN já citadas anteriormente neste trabalho, em seu documento referente à Educação Básica, mais uma vez, o professor Straforini salienta sobre as disciplinas de Geografia e História que as mesmas:

[...] "não aparecem explicitamente enquanto componentes curriculares, mas apenas como um conjunto de conhecimentos em que a base comum deverá ser composta por Língua Portuguesa, Matemática e também "o conhecimento do mundo físico, natural, da realidade social e política, especialmente do Brasil, incluindo-se o estudo da História e das Culturas AfroBrasileira e Indígena" (Grifo nosso). Neste documento ainda é previsto que a formação básica das crianças se dará a partir do "i) desenvolvimento da capacidade de aprender, tendo como meios básicos o pleno domínio da leitura, da escrita e do cálculo; ii) foco central na alfabetização, ao longo dos 3 (três) primeiros anos." (grifo nosso). (STRAFORINI, 2016, p. 163 e 164).

Ao que compete à geografia escolar dos anos iniciais, tais desencontros presentes nas diretrizes curriculares oferecem um risco eminente de interpretação dessas normas pelos sujeitos envolvidos na estrutura curricular que trata da ciência geográfica do Ensino Fundamental.

Já sobre os PCN's, documento oficial que alicerça a listagem dos conteúdos de todos os anos desta primeira etapa do E.F, assumiu no final da década de 1990 uma postura de centralização nacional sobre as metodologias para as práticas pedagógicas no país. Desde seu início, já apresentavam problemáticas vivenciadas no campo da ciência geográfica que ultrapassam questões de 
cunho epistemológico e de seus pressupostos teóricos, por exemplo, o abandono de conteúdos fundamentais, bem como suas categorias de análise; modismos por temas mais atuais sem fazer relação com o conteúdo; valorização da dicotomia entre a geografia física e geografia humana; memorização e mecanização dos conteúdos fazendo parte dos métodos de ensino e sobre a noção de escala e tempo pouco evidente, o que prejudica uma melhor compreensão do espaço geográfico.

Postas essas problemáticas, ainda em um dos seus capítulos "Aprender e ensinar Geografia no Ensino Fundamental", os PCN"s expõem o tradicional discurso, o qual o professor faz par com o livro didático que abrange metodologias descritivas e descontextualizadas do lugar, além de exercícios de memorização também fazerem parte desta realidade. Em suma, os PCN"s se apresentam como uma proposta flexível, mas que desempenham interesses neoliberais através do esteio da sociedade enquanto conhecimento e informação. Na perspectiva desses parâmetros com relação a organização dos conteúdos previstos ao referido nível de escolaridade, os mesmos destacam:

O projeto educacional expresso nos Parâmetros Curriculares Nacionais demanda de uma reflexão sobre a seleção de conteúdos, como também uma ressignificação, em que a noção de conteúdo escolar se amplia para além dos fatos e conceitos passando a incluir procedimentos, valores, normas e atitudes. (BRASIL, 1997, p.73).

Colocadas as ressalvas sobre as competências dos PCN"s, tal documento orienta para a Geografia do ensino fundamental uma série de objetivos referentes à construção da aprendizagem a partir da relação sociedade e natureza, em contexto ao espaço e a paisagem, estabelecidos como categorias a esse aprendizado. São os objetivos consistem na capacitação dos alunos:

1) Conhecer a organização do espaço geográfico e o funcionamento da natureza em suas múltiplas relações, de modo a compreender o papel das sociedades em sua construção e na produção do território, da paisagem e do lugar; 2) identificar e avaliar as ações dos homens em sociedade e suas consequências em diferentes espaços e tempos, de modo a construir referenciais que possibilitem uma participação propositiva e reativa nas questões socioambientais locais; 3) compreender a espacialidade e temporalidade dos fenômenos geográficos estudados em suas dinâmicas e interações; 4) compreender que as melhorias nas condições de vida, os direitos políticos, os avanços técnicos e tecnológicos e as transformações socioculturais são conquistas decorrentes de conflitos e acordos, que ainda não são usufruídas por todos os seres humanos e, dentro de suas possibilidades, empenharse em democratizá-las; 5) conhecer e saber utilizar procedimentos de pesquisa da Geografia para compreender o espaço, a paisagem, o território e o lugar, seus processos de construção, identificando suas relações, problemas e contradições; 6) fazer leituras de imagens, de dados e de documentos de diferentes fontes de informação, de modo a interpretar, analisar e relacionar informações sobre o espaço geográfico e as diferentes paisagens; 7) saber utilizar a linguagem cartográfica para obter informações e representar a espacialidade dos fenômenos geográficos; 8) valorizar o patrimônio sociocultural e respeitar a sociodiversidade, reconhecendo-a como um direito dos povos e indivíduos e um elemento de fortalecimento da democracia (BRASIL, 2001, p. 122).

Perfazendo o que os PCN"s orientam em vista da seleção e organização dos conteúdos, cabe ao professor ter a sensatez em sua reflexão quanto a aplicabilidade das questões que concernem os conteúdos de Geografia como a identidade do lugar, a consciência cidadã e a valorização cultural, entre outros aspectos relevantes ao lugar vivido pelos alunos. Ou seja, progredindo nesta perspectiva, acompanham junto aos objetivos dos PCN"s a efetivação básica de conceitos do conhecimento geográfico, como por exemplo, lugar e paisagem aliados às práticas pedagógicas na rotina escolar dos anos iniciais. Neste sentido, mais uma vez os PCN"s fortalecem e orientam:

No que se refere ao ensino fundamental, é importante considerar quais são as categorias da Geografia mais adequadas para os alunos em relação à sua faixa etária, ao momento da escolaridade em que se encontram e às capacidades que se espera que eles desenvolvam. 
Embora o espaço geográfico deva ser o objeto central de estudo, as categorias paisagem, território e lugar devem também ser abordadas, principalmente nos ciclos iniciais, quando se mostram mais acessíveis aos alunos, tendo em vista suas características cognitivas e afetivas (BRASIL, 2001, p. 75).

Contanto, partimos do entendimento que tais orientações, questionamentos e preocupações previstas no referido parâmetro, não se configuram como uma cartilha de regras, mas que sim, visam promover reflexões quando amparadas de objetivos, categorias e orientações predispostas à melhoria da educação nas disciplinas desta fase do ensino fundamental, sendo pertinente, também, aclarar que houve a identificação de diversas falhas nos PCN"s, sobretudo nos anos inicias na disciplina de Geografia, consequentemente, designando uma cautela ainda maior pelo professor no tratamento de suas práticas ao componente curricular supracitado.

\section{Um olhar teórico sobre o poder do currículo...}

Partindo do raciocínio de ressaltar as relações de poder que consistem os currículos pedagógicos dando-se a partir de referencias teóricos que tratam o termo "poder" e "currículo". ao pensarmos na organização do território e das sociedades, o Estado, por exemplo, apoiado pelo discurso geográfico, conseguimos perceber que o mesmo exerce uma função de ordenar socialmente e espacialmente o seu território. Percebemos que este ordenamento perpassa questões de saúde pública, de segurança, de circulação de produtos e pessoas, e também, em questões sobre o ensino que é repassado à sociedade, através dos currículos. Ancorados pelo filósofo Michel Foucault, é possível compreendermos os principais mecanismos de poder presentes no Estado. Foucault, não presumia em seus textos a criação de uma teoria geral do poder, mas sim, promover a discussão por onde o poder perpassa e quais seus procedimentos e seus efeitos para a sociedade. Complementa ainda:

Logo, só poderia ser, no máximo, e só pretende ser, no máximo, um início de teoria, não do que é o poder, mas do poder, contanto que se admita que o poder não é justamente, uma substância, um fluido, algo que decorreria disto ou daquilo, mas simplesmente na medida em que se admita que o poder é um conjunto de mecanismos e de procedimentos que têm como papel ou função e tema manter - mesmo que não o consigam - justamente o poder. É um conjunto de procedimentos, e é assim e somente assim que se poderia entender que a análise dos mecanismos de poder dá início a algo como a teoria do poder. (FOUCAULT, 2008. p.4)

Para Foucault, o poder não se estabelece em si mesmo e nem começa partir de si mesmo, ou seja, se estabelece em decorrência dos mecanismos e de procedimentos que objetivam o poder. Mecanismos, conforme Foucault chama de mecanismos de poder, fazem parte de todas as relações, sendo próprios destas relações, tanto as familiares, como as escolares no nosso caso de estudo, e até mesmo nas relações sexuais. Assim colocado, concebemos o poder presente em tudo e em todos não se restringindo, apenas, nas relações do Estado.

Para justificarmos e concluirmos sobre o ponto de vista do autor, o mesmo aponta que tudo aquilo que fizemos é política, e que sempre há a escolha de um lado, e ao escolhermos este lado, estabelecemos uma relação de política ao defendermos uma ideia, tomamos um partido e, por conseguinte, se estabelece as relações de poder.

Noutro viés, o currículo pode ser também entendido a partir da análise de cinco (5) âmbitos diferenciados, conforme SACRISTÁN (2000) salienta: 1) ponto de vista sobre sua função social como ponto entre a sociedade e a escola; 2) projeto ou plano educativo, pretenso ou real, composto de diferentes aspectos, experiências, conteúdos, etc.; 3) currículo como expressão formal e material desse projeto sob determinado formato, conteúdo, orientação e sequencia para abordá-lo; 4) currículo como 
um campo prático, onde se analisa os processos instrutivos e a realidade da prática a partir de uma perspectiva que lhes dota de conteúdo, como um território de inserção de práticas diversas e com um discurso sobre a interação entre a teoria e a prática em educação; 5) referenciado aos que exercem atividade acadêmica ou pesquisadora sobre estes temas. Para Sacristán, o currículo se cristaliza como a reflexão entre teoria e a prática e que deve ser modificada constantemente, isto é, os currículos representam expressões de equilíbrio dos interesses e forças que gravitam sobre o sistema educativo, carregado de valores e de pressupostos os quais se faz necessário decifra-los. Do sistema educativo, assim, acaba sendo sobreposto por esses interesses e é refletido nos currículos. Tais valores e interesses tornam-se ocultos no currículo e, do que realmente reflete deles, é o esquema socializador que têm, além de tudo, o caráter formativo e cultural que as escolas irão se propor a transmitir.

Depreendendo tal concepção, Sacristán afirma que o documento simboliza um mecanismo através do qual o conhecimento é disseminado socialmente, pois adota um caráter de intervenção social que refletirá nas escolhas dos grupos dominantes de uma sociedade. Ou seja, se o currículo é prática como mencionado anteriormente, os indivíduos que participam da sua construção e da sua reflexão são os sujeitos, elementos ativos deste processo de elaboração.

Pelo desenvolvimento deste texto, se faz possível concluir próximo o currículo como um instrumento de poder. Durante o nosso entendimento sobre este estudo, constatamos também, a instabilidade dos documentos que norteiam a estruturação do currículo.

\section{Considerações Finais}

Dos pareceres e novas versões de documentos acabamos por perceber que, invariavelmente, os mesmos se apresentam como inovadores e com um discurso redentor de que a geografia deve ser ensinada, mas que deveras, acabam por produzir uma desorientação àqueles que carecem por colocar em prática toda a organização e conhecimento que envolve um componente curricular dos anos iniciais enquanto diretriz para a Educação Básica.

Depreendemos que a geografia prevista para os anos iniciais mediante a tantas orientações de cunho epistemológico - metodologias, objetivos e conteúdos nos textos curriculares dos PCN"s (assim como os demais documentos), pouquíssimo são apropriados aos professores responsáveis por ministrar neste nível de ensino porque a elaboração desses documentos oficiais, seus textos, em momento algum, foram produzidos pelos profissionais que atuam nos anos iniciais e sempre por uma comunidade disciplinar específica, neste ensejo a disciplina de Geografia, que acaba acarretando em responder suas próprias interrogações ao invés de estabelecer um diálogo mais plausível e eficiente com a Pedagogia e elaborar respostas que edifiquem uma organização curricular a qual o professor consiga se identificar e compreender e dar o verdadeiro sentido ao uso de documentos curriculares que visam, de fato, uma parametrização.

Frente a essa realidade descrita nos documentos curriculares, nos tenciona a uma reflexão, imprescindível, no que diz respeito ao currículo das unidades escolares. Pois, neste momento em que discutimos a geografia no cenário curricular dos anos iniciais, despontou de nossa parte um interesse de delimitar por meio desses documentos a intenção dos discursos que, por sua vez, consistem na produção de sentidos. Sentidos estes que servem, geralmente, como suporte norteador aos professores responsáveis de ministrar o conteúdo dos componentes curriculares nos anos iniciais.

Por fim, podemos constatar que dessa gama de publicações referentes a esses documentos curriculares é possível identificar nos seus discursos que, apesar das suas inconsistências, alterações e lacunas, um discurso equivalente persiste entre eles, isto é, prevalece o discurso hegemônico e permanente do que necessárias modificações concernentes a esta geografia escolar disciplinarizada, aonde se evidencia a importância do poder do currículo escolar na construção de saberes e valores.

\section{Referências}

BRASIL, Ministério da Educação. Parâmetros Curriculares Nacionais. História e Geografia. Brasília: MEC/SEF, 1997.

\footnotetext{
ParaOnde!?, Porto Alegre, v.10, n.2, p.142-148, 2018. Edição Especial com artigos publicados originalmente na XII ENANPEGE
} http://seer.ufrgs.br/paraonde 
BRASIL. Parâmetros curriculares nacionais: história, geografia. Brasília: MEC/SEF, 1997.

BRASIL. Parecer $C N E / C E B n^{\circ} 11$ de 9 de dezembro de 2010. Diretrizes Curriculares Nacionais para o Ensino Fundamental de 9 (nove) anos.

BRASIL. Resolução CNE/CBE $n^{\circ} 02$ de 7 de abril de 1998. Diretrizes Curriculares Nacionais para o Ensino Fundamental.

BRASIL. Resolução $C N E / C P n^{\circ} 1$ de 15 de maio de 2006. Diretrizes Curriculares Nacionais para os Cursos de Graduação em Pedagogia, licenciatura.

BRASIL, Ministério da Educação. Secretária da Educação Básica. Ensino Fundamental de nove anos Orientações Gerais. Brasília, 2004.

CAMPOS, Rui Ribeiro de. Breve Histórico do Pensamento Geográfico Brasileiro nos séculos XIX e XX. Jundiaí, SP: Paco Editorial, 2011.

FOUCAULT, Michel. Segurança, território, população. São Paulo: Livraria Martins Fontes Editora Ltda, 2008.

. Microfísica do poder. Rio de Janeiro: Edições Graal, 2011.

SACRISTÁN, J. Gimeno. O Currículo: uma reflexão sobre a prática. Porto Alegre: Artmed, 2000.

STRAFORINI, Rafael. Ensinar Geografia: o desafio da totalidade-mundo nas séries iniciais. 2 $2^{\text {a }}$ edição. São Paulo: Annablume, 2004.

. O ensino de Geografia nas séries iniciais do ensino fundamental: um olhar a partir dos registros de classes de seus sujeitos praticantes. In: BENTO, I. P.; OLIVEIRA, K. A. T. de (orgs.). Formação de professores: pesquisa e prática pedagógica em geografia. 1 ed. Goiânia: Editora PUC/Goiás, 2012, v.1, p. 79-101.

. O Currículo de Geografia do Ensino Fundamental: entre conhecer o que se diz e o vivenciar o que se pratica. In: Ivaine Maria Tonini; Lígia Beatriz Goulart; Rosa Elisabete Militz Wypyczynsky Martins. (Org.). O Ensino de Geografia e suas composições curriculares. 1ed.Porto Alegre: Mediação, 2014, v. , p. 43-60.

Permanência e mudanças no currículo de geografia dos anos iniciais do Ensino Fundamental. Revista Brasileira de Educação em Geografia, Campinas, v. 6, n. 11, p.160-184, jan./jun., 2016. 